\title{
In vitro demineralization prevention by fluoride and silver nanoparticles when applied to sound enamel and enamel caries-like lesions of varying severities
}

Short Title: Caries prevention via Fluoride and Silver

Bader A. Aldhaian ${ }^{1,2}$, Abdulrahman A. Balhaddad ${ }^{3}$, Areej A. Alfaifi ${ }^{1,2}$, John A. Levon ${ }^{1}$, George J. Eckert ${ }^{4}$, Anderson T. Hara ${ }^{5}$, Frank Lippert ${ }^{5 *}$

1 - Indiana University School of Dentistry, Department of Prosthodontics, 1121 W Michigan St., Indianapolis, IN, 46202, USA

2 - King Saud Bin Abdulaziz University for Health Sciences, College of Dentistry, Department of Prosthodontics, Riyadh, Saudi Arabia

3 - Department of Restorative Dental Sciences, Imam Abdulrahman Bin Faisal University, College of Dentistry, Dammam, Saudi Arabia

4 - Indiana University School of Medicine, Department of Biostatistics, 410 W. Tenth St., Suite 3000, Indianapolis, IN, 46202, USA

5 - Indiana University School of Dentistry, Department of Cariology, Operative Dentistry and Dental Public Health, 1121 W Michigan St, Indianapolis, IN 46202, USA

\section{*Corresponding author:}

Indiana University School of Dentistry

Department of Cariology, Operative Dentistry and Dental Public Health

Oral Health Research Institute

415 Lansing Street

Indianapolis, IN, 46202, USA

Tel. +1 317274 3983, Fax +1 317274 5425, E-mail address: flippert@iu.edu

Keywords: Dental caries; Microradiography; Fluoride; Silver; Nanoparticles; Demineralization

This is the author's manuscript of the article published in final edited form as: 


\begin{abstract}
Objectives: To investigate the effect of fluoride and silver nanoparticles on the prevention of in vitro demineralization of sound enamel and enamel caries-like lesions of varying severities.

Methods: Caries-like lesions of different severities (1/6/15 days) were created in bovine enamel specimens. One group remained sound. All specimens were demineralized again using a partially saturated acetic acid solution. Mimicking the intra-oral retention of fluoride and silver in vitro, this solution was supplemented with fluoride (0/1/10 ppm) and/or silver nanoparticles ( $0 / 10 \mathrm{ppm})$ in a factorial design. Changes in lesion depth $(\Delta \mathrm{L})$ and integrated mineral $\operatorname{loss}(\Delta \Delta \mathrm{Z})$ were evaluated by digital transverse microradiography. Data was analyzed using three-way ANOVA.
\end{abstract}

Results: Lesion severity significantly affected $\Delta \Delta \mathrm{Z}$ and $\Delta \mathrm{L}$, after no treatment and after the treatment of fluoride and silver independently ( $\mathrm{p}=0.012$ and $\mathrm{p}=0.037$, respectively). Fluoride and the fluoride $\times$ lesion severity interaction were shown to be significant $(\mathrm{p}<0.001)$ on $\Delta \Delta \mathrm{Z}$ and $\Delta \mathrm{L}$. Silver nanoparticles significantly affected $\Delta \Delta \mathrm{Z}(\mathrm{p}=0.041)$, but not $\Delta \mathrm{L}(\mathrm{p}=0.15)$. The silver nanoparticles $\times$ lesion severity interaction was significant for $\Delta \Delta \mathrm{Z}$ and $\Delta \mathrm{L}$ ( $\mathrm{p}=0.032$ and $\mathrm{p}=0.024$, respectively). No interaction was observed for $\Delta \Delta \mathrm{Z}$ and $\Delta \mathrm{L}$ between fluoride and silver ( $\mathrm{p}=0.962$ and $\mathrm{p}=0.971$, respectively) as well as lesion severity and the use of fluoride and silver combined ( $\mathrm{p}=0.722$ and $\mathrm{p}=0.158$, respectively).

Conclusion: Fluoride and silver nanoparticles had a significant effect on the prevention of in vitro demineralization of sound enamel and enamel caries-like lesions of varying severities.

Clinical significance: Fluoride and silver nanoparticles may potentially allow for more tailored caries prevention. 


\section{Introduction}

Dental caries is one of the most prevalent chronic diseases worldwide; affecting approximately $60-90 \%$ of children, nearly $100 \%$ of adults and consequently causing pain and discomfort [1]. Caries can be defined as the confined demolition of prone dental hard tissues by acidic byproducts from bacterial fermentation of carbohydrates consumed from the diet [2]. The disease process initially starts within the bacterial biofilm (dental plaque) that covers a tooth surface and long before the signs of the carious demineralization can be clinically detected $[3,4]$.

Caries can be prevented by implementing strategies such as increasing the resistance of the host, modifying or eliminating pathogenic microbes and lessening the impact of a cariogenic diet [5]. Considering self-care, fluoridated toothpaste is thought of as one of the most powerful interventions for caries prevention. A Cochrane review of 71 randomized or quasi-randomized controlled trials concluded that fluoride toothpastes containing $1,000 \mathrm{ppm}$ fluoride or more are effective in prevention of caries [6].

An array of chemotherapeutic agents have been examined as a strategy to prevent and arrest dental caries such as the use of metal ions, antimicrobials and a variety of fluoride compounds $[8,9]$. Silver diamine fluoride (SDF) has been reviewed recently in the literature as a potential anti-caries compound. SDF possesses the capability of preventing the incidence of new caries lesions and arresting the existing ones [10]. However, owing to the oxidation of ionic silver within its chemical composition, SDF causes the carious tissue to be stained black. It also causes some mildly painful lesions when it accidentally comes in contact with the oral mucosa [9]. These drawbacks have led researchers to develop nano silver fluoride compounds (NSF) [11-12]. NSF advanced to be a promising anti-caries agent [11]. The new material combines the preventive and antimicrobial properties against the primary pathogens liable for the development of dental caries [12]. It overcomes the adverse effects of SDF in that NSF

does not stain the dental tissue black. Furthermore, a number of studies have demonstrated that silver nanoparticles possess antimicrobial properties [13,14]. However, no study has thus far investigated whether silver nanoparticles interfere in the de-and remineralization of early caries lesions.

The nanoparticles of the NSF's spherical shape and small size $(3.2 \pm 1.2 \mathrm{~nm})$ increases the contact surface, which effectively enhances the antimicrobial properties $[15,16]$. In a study by Targino et al. [17], the antimicrobial and cytotoxic activity of NSF, chlorhexidine and SDF was compared. They found that NSF is bacteriostatic and bactericidal. It was calculated that NSF was 
more biocompatible than SDF and not toxic at the used concentrations for any type of red blood cells.

The effect of fluoride and silver nanoparticles in the prevention of dental caries has been established in the literature, however Bjarnason and Finnbogason [18] have demonstrated that the effectiveness of fluoride depends on the timing of its introduction into the caries process. They concluded that "higher fluoride levels in the dentifrice are more effective in retarding the initiation of caries, while they do not differ with respect to the progression of radiographically detectable approximal carious lesions".

Furthermore, contemporary reviews $[19,20,21]$ as well as clinical studies [22,23] did indicate that fluoride concentrations in the oral environment may have an influence on the progression and remission of dental caries.

This highlights the need for an in vitro study utilizing fluoride and silver concentrations similar to those found in plaque fluid rather than studying their effect as topical treatments [24].

Therefore, the primary aim of the present laboratory study was to investigate the effect of fluoride and silver nanoparticles on the prevention of cariogenic demineralization of sound enamel and enamel caries-like lesions of varying severities. The secondary aim was to determine if fluoride and silver exhibit additive or synergistic effects in preventing demineralization. The null hypothesis was that fluoride and silver nanoparticles did not have a significant effect in the prevention of demineralization of sound enamel and enamel carieslike lesions of varying severities.

\section{Material and Methods}

\subsection{Study Design}

Early caries-like lesions were created in bovine enamel specimens and assigned to 24 treatment groups ( $\mathrm{n}=15$ per group). Lesions (three severities) and sound enamel specimens were then exposed to a plaque fluid-like solution varying in fluoride $(0 ; 1$; or $10 \mathrm{ppm})$ and silver nanoparticles concentration $(0$ or $10 \mathrm{ppm})$ for $72 \mathrm{~h}$ in a 4 (specimen types) $\times 3$ (fluoride) $\times 2$ 
(silver) factorial design. The resulting changes in mineral distribution profiles of the specimens were determined using digital transverse microradiography (TMRD) after lesion creation and exposure to plaque fluid-like solutions. Changes in integrated mineral loss $(\Delta \Delta \mathrm{Z})$ and lesion depth $(\Delta \mathrm{L})$ were calculated from these data and served as the outcome variable.

Figure 1 shows the experimental design of the study concerning different lesion severities and different fluoride and silver nanoparticles concentrations. One group of specimens remained sound, whereas early caries lesions of different severities were formed in the other specimens.

\subsection{Specimen Preparation}

Enamel specimens were obtained from 613 bovine teeth (Tri State Beef, Cincinnati, OH, USA). Tooth crowns were cut into $5 \times 5 \mathrm{~mm}$ specimens using a low-speed saw (IsoMet, Buehler, Lake

Bluff, IL, USA). The teeth were stored in water containing thymol during the sample preparation process. Specimens were ground and polished to create flat planar parallel dentin and enamel surfaces using an automated grinding and polishing machine (Rotopol 31/Rotoforce 4 polishing unit, (Struers, Cleveland, OH, USA). The dentin side of the specimens were ground flat to a uniform thickness with 500-grit silicon carbide grinding paper (MDFuga, Struers). The enamel side of the specimen were serially ground using 1,200-, 2,400- and 4,000 grit paper. The specimens were then polished using a 1- $\mu \mathrm{m}$ diamond polishing suspension (DP-Suspension P, Struers) on a polishing cloth (MD-Dac, Struers) until the enamel surface had a minimum of a 4.5 $\times 4.5 \mathrm{~mm}$ highly polished facet across the specimen. Resulting specimens had a thickness range of 1.7-2.2 mm. The specimens were assessed under a stereo-microscope (SMZ 1500, Nikon, Melville, NY, USA) at 20× magnification for cracks, hypomineralized (white spots) areas or other flaws in the enamel surface that would exclude them from use in the study. Prepared specimens were then stored at $100 \%$ relative humidity at $4{ }^{\circ} \mathrm{C}$ until further use. The final sample number was 420 divided into 24 groups resulting in 15 samples per group (we prepared 60 more specimens than needed to allow for exclusion of outliers). A schematic drawing of an enamel specimen is shown in Figure 2.

\subsection{Artificial Caries Lesion Creation (Primary Demineralization)}

In vitro incipient caries lesions were prepared using a partially saturated lactic acid solution as described previously [25]. Sound enamel specimens were immersed in a demineralization 
solution containing 0.1 M lactic acid, $4.1 \mathrm{mM} \mathrm{CaCl} 2 \times 2 \mathrm{H} 2 \mathrm{O}, 8 \mathrm{mM} \mathrm{KH} 2 \mathrm{PO} 4$ (Fisher Scientific, Fair Lawn, NJ, USA) and 0.2\% w/v Carbopol 907 (BF Goodrich, Akron, OH, USA), pH adjusted to 5.0 using $\mathrm{KOH}$ (Fisher Scientific) at $37^{\circ} \mathrm{C}$. To create lesions of different severities, demineralization periods of 1,6 , and 15 days were chosen (Figure 1). One group of enamel specimens remained sound ( 0 day demineralization). After lesion creation, specimens were rinsed with deionized water and air-dried. Approximately, half of the lesion surface area was covered with acid-resistant nail varnish (Advanced Hard as Nails Nail Polish, Sally Hansen, New York, NY, USA) to protect a lesion baseline area for subsequent analysis. Specimens were then stored at approximately $100 \%$ relative humidity at $4{ }^{\circ} \mathrm{C}$ until further use.

\subsection{Secondary Demineralization}

All lesions and the group of specimens that remained sound were demineralized (again) at $37{ }^{\circ} \mathrm{C}$ and for $72 \mathrm{~h}$ using a partially saturated acetic acid solution with the following composition: $50 \mathrm{mM}$ acetic acid, $2.25 \mathrm{mM} \mathrm{CaCl} 2 \times 2 \mathrm{H} 2 \mathrm{O}, 1.35 \mathrm{mM} \mathrm{KH} 2 \mathrm{PO} 4$ and $130 \mathrm{mM} \mathrm{KCl}$ (Fisher Scientific), pH adjusted to 5.0 with $\mathrm{KOH}$ [26]. This solution was supplemented with fluoride and/or silver nanoparticles (ASAP HCP Health Max 30 Immune System Support Silver Supplement, SilverSol Technology, American Biotech Labs, Utah, USA) at varying concentrations according to Figure 1. According to the manufacturer, SilverSol Technology uses a unique silver nanoparticle that has a patented silver oxide coating (Ag4O4) and supercharged with the same frequency as the UltraViolet light. The manufacturer claims that this combination makes SilverSol at $10 \mathrm{ppm}$ more effective than colloidal and ionic silver. A fluoride- and silver-free control was included as negative control.

\subsection{Transverse Microradiography (TMRD)}

Sections, one per specimen and approximately $100 \mu \mathrm{m}$ in thickness, were cut across the lesion window, incorporating both lesion baseline and secondary demineralization areas (Figure 2), using a hard tissue microtome (Silverstone-Taylor Hard Tissue Microtome, Scientific Fabrications Laboratories, Lafayette, CO, USA). Initially sound specimens were sectioned in a similar fashion. The sections were placed in the TMR-D system (Inspektor Research Systems BV, Amsterdam, The 
Netherlands) and X-rayed at $45 \mathrm{kV}$ and $45 \mathrm{~mA}$ at a fixed distance of $20 \mathrm{~cm}$ for $12 \mathrm{~s}$. An aluminum step wedge was X-rayed under identical conditions. The digital images were analyzed using the TMR software v.3.0.0.18. Sound enamel was assumed to be $87 \% \mathrm{v} / \mathrm{v}$ mineral. Then, lesions were analyzed and the following parameters calculated: $\Delta \mathrm{Z}$ - integrated mineral loss; $\mathrm{L}-$ lesion depth. The study variables for the demineralized specimens were calculated as follows: changes in integrated mineral loss: $\Delta \Delta \mathrm{Z}=\Delta \mathrm{Z}_{\text {sound }}-\Delta \mathrm{Z}_{\text {post }}(\Delta \Delta \mathrm{Z}>0$ is indicative of lesion remineralization after secondary demineralization, whereas $\Delta \Delta Z<0$ would indicate further lesion demineralization); changes in lesion depth : $\Delta \mathrm{L}=\mathrm{L}_{\text {post }}-\mathrm{L}_{\text {sound }}(\Delta \mathrm{L}<0$ is indicative of reduction in lesion depth after secondary demineralization, whereas $\Delta \mathrm{L}>0$ would indicate a further increase in lesion depth). For the initially sound enamel specimens, we only determined $\Delta \mathrm{Z}$ and $\mathrm{L}$.

\subsection{Statistical Analysis}

$\Delta \mathrm{Z}$ and $\mathrm{L}$ were summarized after the 1 st and 2 nd demineralization periods by study group. $\Delta \Delta \mathrm{Z}$ and $\Delta \mathrm{L}$ were calculated and summarized by study group. Summary statistics included mean, standard deviation, standard error, 95\% confidence interval for the mean, and range. Paired ttests were used to test whether $\Delta \Delta \mathrm{Z}$ and $\Delta \mathrm{L}$ were significantly different from zero within each study group. Three-way analysis of variance (ANOVA) was used to determine the effects of $1^{\text {st }}$ stage demineralization time $(0,1,6,15 \mathrm{~d})$, fluoride $(0,1,10 \mathrm{ppm})$, and silver nanoparticles $(0,10$

$\mathrm{ppm})$ on $\Delta \Delta \mathrm{Z}$ and $\Delta \mathrm{L}$. The interactions between fluoride and silver nanoparticles were used to determine if fluoride and silver exhibit additive or synergistic effects in preventing demineralization. The distributions of the study outcomes were examined and a transformation of the data (e.g. logarithmic, rank) were used when necessary. A 5\% significance level was used for all tests. Analyses were performed using statistical software SAS version 9.4 (SAS version 9.4 SAS Institute Inc., Cary, NC, USA).

\section{Results}

The sound enamel and caries-like lesion baseline data for all treatment groups Changes in lesion variables after secondary demineralization are shown in Table 1 by lesion protocol, fluoride, an 
treatment data can be found in Figures 3-5. The results obtained varied in their pattern. In general, fluoride and silver nanoparticles had a favorable effect on the study parameters in a dose response manner;, i.e.,: reducing mineral loss and lesion depth increasing the surface mineral density by enhancing mineral deposition. Also, the effects of fluoride and silver nanoparticles were both significantly affected by lesion severity.

\subsection{Lesions severity $\times$ fluoride $\times$ silver interaction}

The results of the three-way ANOVA show that lesion severity significantly affected the values of the study parameters, change in mineral loss $(\Delta \Delta \mathrm{Z})$ and lesion depth $(\Delta \mathrm{L})$, after no treatment and after the treatment of fluoride and silver independently $(\mathrm{p}=0.012$ and $\mathrm{p}=0.037$, respectively). Fluoride as well as fluoride $\times$ lesion severity interaction were shown to have a significant effect $(\mathrm{p}<0.001)$ on $\Delta \Delta \mathrm{Z}$ and $\Delta \mathrm{L}$. Silver nanoparticles significantly affected the change in mineral loss $(\Delta \Delta \mathrm{Z})(\mathrm{p}=0.041)$ but not the lesion depth $(\Delta \mathrm{L})(\mathrm{p}=0.15)$. On the other hand silver nanoparticles $\times$ lesion severity interaction effect was of a statistical significant for $\Delta \Delta \mathrm{Z}$ and $\Delta \mathrm{L}$ ( $\mathrm{p}=0.032$ and $\mathrm{p}$ $=0.024$, respectively).

No interaction was observed between fluoride and silver for $\Delta \Delta \mathrm{Z}$ and $\Delta \mathrm{L}(\mathrm{p}=0.962$ and $\mathrm{p}=0.971$, respectively) as well as lesion severity and the use of fluoride and silver combined when the two parameters were investigated $(\mathrm{p}=0.722$ and $\mathrm{p}=0.158$, respectively).

\subsection{Mineral loss $(\Delta \Delta Z)$ following fluoride exposure}

All the groups demonstrated a statistically significant mineral loss $(\Delta \Delta \mathrm{Z})$ from baseline to post except $10 \mathrm{ppm}$ fluoride on day 1 , which showed a significant mineral gain, and $1 \mathrm{ppm}$ fluoride on day 0 and $10 \mathrm{ppm}$ fluoride on day 6, which showed no significant change (Figure 3A). $10 \mathrm{ppm}$ fluoride was found significantly effective in minimizing the amount of mineral loss compared to control in day 0,1 , and 6 . However, no significant difference was found at day 15 ,. while the use of $1 \mathrm{ppm}$ fluoride was found to have a significant effective only at day 0 .

\subsection{Lesion depth $(\Delta L)$ following fluoride exposure}

All the groups showed a statistically significant increase in lesion depth $(\Delta \mathrm{L})$ from baseline to post except 10 ppm on day 1 , which showed a statistically significant decrease in lesion depth, and 1 ppm and $10 \mathrm{ppm}$ on day 0 and $1 \mathrm{ppm}$ on day 15 , which showed no significant change 
(Figure 3B). In the day 0 group, the control had significantly higher $\Delta \mathrm{L}$ than $(1 \mathrm{ppm}$ and 10 ppm) fluoride but there was no difference between $1 \mathrm{ppm}$ and $10 \mathrm{ppm}$. In the day 1 group, the control showed less increase in $\Delta \mathrm{L}$ than $1 \mathrm{ppm}$ fluoride and the $10 \mathrm{ppm}$ fluoride showed a reduction in lesion depth. No significant difference was found between the selected fluoride concentrations and control at day 6. In the day 15 group, the control and $1 \mathrm{ppm}$ were significantly lower than $10 \mathrm{ppm}$ fluoride.

\subsection{Mineral loss $(\Delta \Delta Z)$ following silver exposure}

All the groups showed a statistically significant mineral loss $(\Delta \Delta Z)$ from baseline to post except $10 \mathrm{ppm}$ silver on day 15 , which was not statistically significant (Figure 4A). In the day 0 and day 6 groups, the effect was statistically significant between the control and $10 \mathrm{ppm}$ silver in reducing the mineral loss but not the other remaining groups.

\subsection{Lesion depth $(\Delta L)$ following silver exposure}

All the groups showed a statistically significant increase in lesion depth $(\Delta \mathrm{L})$ from baseline to post except $10 \mathrm{ppm}$ silver on day 15, which was not statistically significant (Figure 4B). The control ( 0 ppm silver) had significantly higher $\Delta \mathrm{L}$ than $10 \mathrm{ppm}$ silver on day 0 group ( $\mathrm{p}=0.015)$, but silver had no significant effect on $\Delta \mathrm{L}$ for other days ( $\mathrm{p}>0.10$ ).

\subsection{Caries lesion mineral distribution}

In general, changes in mineral distribution were affected by both fluoride and silver (Figure 45). In the initially sound specimens (Figure 5A), little demineralization can be noted in the presence of even $1 \mathrm{ppm} \mathrm{F}$. The effect of silver, however, was indistinguishable from that of the control, and silver did not alter the effect of fluoride. In the 1-day lesions (Figure 5B), silver appears to reduce the extent of surface mineralization in the presence or absence of fluoride. However, this was not noted in the initially more demineralized lesions (Figures 5C-D). Silver led to slightly more demineralization in the lesion body compared to the control; however, silver prevented further mineral loss, albeit only marginally, from the lesion body in the presence of $1 \mathrm{ppm} \mathrm{F}$. In the presence of $10 \mathrm{ppm} \mathrm{F}$, silver prevented remineralization and in particular close to the lesion surface. In the 6-day lesions (Figure 5C), silver did not only prevent demineralization but caused some remineralization in comparison to the control and in the outer parts of the lesion 
(up to a lesion depth of approx. $40 \mu \mathrm{m}$ ). However, silver had little effect on deeper parts within the lesion. When co-present with and in comparison to $1 \mathrm{ppm} \mathrm{F}$, silver enhanced remineralization at a lesion depth range of approx. 20-50 $\mu \mathrm{m}$ and prevented demineralization in the original lesion body. When co-present with and in comparison to $10 \mathrm{ppm} \mathrm{F}$, silver prevented demineralization beyond the original lesion and enhanced remineralization close to the lesion surface but not of the surface layer. The 15-day lesions (Figure 5D) appeared to be the least responsive compared to the other study substrates as considerably less remineralization and further demineralization were noted and regardless of the presence or absence of fluoride and silver. Silver again prevented demineralization beyond the original lesion, however not when co-present with 10 ppm F. Interestingly, silver also led to at least numerically the greatest extent of lesion surface and near-surface remineralization, however again only in the absence of fluoride. When copresent with and in comparison to $1 \mathrm{ppm} \mathrm{F}$, silver negatively impacted the ability of fluoride to enhance remineralization in the outer parts of the lesion and prevent further demineralization in the original lesion body. However, when co-present with and in comparison to $10 \mathrm{ppm} \mathrm{F}$, silver did not affect deeper parts of the lesion but prevented demineralization and actually lead to remineralization at a lesion depth range of approx. 20-90 $\mu \mathrm{m}$.

\section{Discussion}

The present in vitro study aimed to investigate the effect of fluoride and silver nanoparticles in the prevention of demineralization of sound enamel and enamel caries-like lesions of varying severities. In laboratory studies of dental caries, artificial caries lesions are generally considered to be suitable surrogates for their in vivo counterparts. Despite this consensus within the research community, it should be noted that in in vivo compared to in vitro caries de- and remineralization processes occur at a considerably smaller rate, $\mathrm{pH}$ fluctuations occur more frequently and are more subtle, and the concentrations of ions artificially introduced into the

oral cavity, such as fluoride and silver, are not constant (see also study limitations 
below). The chosen demineralization protocol for lesion creation was based on a previous study [25], enabling the creation of caries lesions of different severities (early and advanced stages). The secondary demineralization solution was used previously [26] to test the acid resistance of lesions similar to the ones employed in the present study. The secondary demineralization time and fluoride concentrations were chosen to mimic a relatively short, yet high cariogenic attack with fluoride resembling those found in plaque fluid $1 \mathrm{~h}$ after fluoride administration [27]. Likewise, the chosen concentrations of the silver nanoparticles were based on the manufacturer's recommendation. Bovine enamel was used, which offers many advantages over human enamel, for example more uniform enamel thickness, larger surface area and abundancy of unaffected teeth compared to human enamel. For these reasons bovine enamel has been used often in dental research [25,28-30]. Lastly, lesions were analyzed using TMRD, which is the 'gold standard' due to its ability to quantify subsurface mineral distributions and changes thereof.

Currently there has been a shift towards prevention and minimally invasive dentistry as a foundational principle of the practice of modern dentistry. Ten Cate [31] advocated research should focus on novel comprehensive protocols on caries prevention that encompass fluoride and other agents affecting the de- and remineralization balance as well as having antimicrobial properties. A number of effective caries prevention programs as well as various caries arresting agents have been studied to prevent and/or stop the progression of dental caries, including community water fluoridation, school mouth-rinse programs, school dental sealant programs, topical fluoride agents, such as sodium fluoride (NaF), silver diamine fluoride (SDF) and the more recently developed nano-silver fluoride (NSF) [9, 32]. In this context, the concept of minimally invasive/minimal intervention dentistry (MID) must be mentioned which has attracted considerably more attention over the last two decades. It aims to arrest active caries through nonoperative procedures while trying to preserve as much of the natural tooth structure as possible [33]. MID not only involves the aforementioned preventive care with fluorides but also placement of fissure sealants, resin infiltration, atraumatic restorative treatment (ART) and the placement of stainless steel (Hall) crowns [33]. Resin infiltration, for example, has recently been shown to be more efficacious in camouflaging the unappealing esthetics of caries lesions on labial surfaces than a remineralizing intervention containing fluoride and nano-hydroxyapatite [34]. 
The science of nanotechnology has the potential to provide new solutions in the development of caries arresting agents. The nanoparticles' size results in greater surface area to allow for a better and more efficient drug delivery system [2]. The deposition of silver salt and the antibacterial effect of silver ion are the two main mechanisms related to the effect of silver in $\mathrm{AgF}$ in preventing and arresting caries in dentine [35]. Also, another study has concluded that topical application of silver or fluoride ions can increase the mineral density of demineralized enamel and dentine lesions during remineralization [36].

The novel approach undertaken presently was concerned with investigating the ability of silver nanoparticles alone and in combination with fluoride, mimicking when they are retained in plaque fluid, to significantly affect the prevention of cariogenic demineralization of sound enamel and enamel caries lesions of varying severities. Previous studies were concerned with either one but not both. The authors are unaware of previous studies that have tested both factors (fluoride and silver nanoparticles) and their interaction on the prevention of cariogenic demineralization of sound enamel and enamel caries lesions of varying severities. The present study was able to demonstrate a significant effect of fluoride and silver nanoparticles on the prevention of cariogenic demineralization of sound enamel and enamel caries lesions of varying severities. Based on these results the null hypotheses was rejected. In general, the findings obtained showed that fluoride and silver nanoparticles affected the study parameters by reducing mineral loss and lesion depth in a dose response matter (Figure 3) and (Figure 4). The magnitude of this effect was highly dependent on lesion severity ( $\Delta \mathrm{Z}_{\text {lesion }}$ ), as lesions with small $\Delta \mathrm{Z}_{\text {lesion }}$ were more readily demineralized than larger ones. This tends to confirm the findings of Schäfer et al. [37]. This could be explained by the inherent solubility of the chemical structure of the less severe enamel lesions [24 ]. It is believed that the presence of carbonate and magnesium act as impurities in the crystalline microstructure of hydroxyapatite which exerts strain and hence increases the solubility. This shows the importance of the status of the lesion and therefore timing of the caries arrest agent intervention.

The current study failed to show a statistically significant indication of synergistic effects between fluoride and silver nanoparticles. This is in partial agreement with a previous study [36]. The potential reasons are manifold. Fluoride is very reactive with hydroxyapatite and consumed within the outer parts of the lesion, thereby preventing mineral loss within the original lesion body. Acid, however, penetrates further into deeper, more soluble parts of the lesion and 
eventually demineralizes sound enamel and this could explain why the 15-day group showed pronounced effect of silver beyond the original lesion in the sound enamel (Figure 5). Similarly, silver nanoparticles have been shown to bind to hydroxyapatite surfaces and may therefore be consumed in the outer parts of the lesion rather than penetrating into deeper parts of the lesion [38].

The present study undoubtedly had several limitations, with it being a laboratory investigation representing perhaps the most important shortcoming. De- and remineralization processes are considerably different under clinical than laboratory conditions. In particular, the co-presence of salivary proteins, bacteria and yeasts as well as food-derived debris that can accumulate in caries lesions in the oral cavity [39-40] can reduce lesion porosity and ultimately hamper mineral influx. Nanoparticles may also preferentially bind to organic matter which in turn limits their ability to interact with the minerals in enamel. While the utilization of a commercially-available silver nanoparticles allows for other researchers to advance the present investigations, the exact chemical nature of this material is proprietary information. Further studies, with a detailed investigation of the composition of the minerals in the enamel lesions after the remineralization treatments with a microbial model and different concentrations of silver nanoparticles, need to be carried out to confirm the findings of this study.

\section{Conclusion}

Fluoride and silver nanoparticles had a significant effect in preventing in vitro demineralization of sound enamel and enamel caries-like lesions of varying severities. However, considerably more evidence and derived from predominantly clinical research will be needed before silver nanoparticles can be considered for caries prevention.

\section{Declaration of Interest}

The authors declare no conflict of interest.

\section{Ethical approval}


No ethical approval was required prior to the conduct of the present study. 


\section{References}

[1] WHO | What is the burden of oral disease?, WHO. (n.d.). https://www.who.int/oral_health/disease_burden/global/en/ (accessed June 27, 2020).

[2] A.A. Balhaddad, A.A. Kansara, D. Hidan, M.D. Weir, H.H.K. Xu, M.A.S. Melo, Toward dental caries: Exploring nanoparticle-based platforms and calcium phosphate compounds for dental restorative materials, Bioact. Mater. 4 (2019) 43-55, https://doi.org/10.1016/j.bioactmat.2018.12.002.

[3] R.H. Selwitz, A.I. Ismail, N.B. Pitts, Dental caries, Lancet 369 (2007) 51-59, https://doi.org/10.1016/S0140-6736(07)60031-2.

[4] V. Baelum, W. van Palenstein Helderman, A. Hugoson, R. Yee, O. Fejerskov, A global perspective on changes in the burden of caries and periodontitis: implications for dentistry, J. Oral Rehabil. 34 (2007) 872-906; discussion 940, https://doi.org/10.1111/j.13652842.2007.01799.x.

[5] M. Nishi, M. Harding, V. Kelleher, H. Whelton, F. Allen, Knowledge of caries risk factors/indicators among Japanese and Irish adult patients with different socio-economic profiles: a cross-sectional study, BMC Oral Health. 17 (2017), https://doi.org/10.1186/s12903-017-0345-x.

[6] V.C.C. Marinho, J.P. Higgins, A. Sheiham, S. Logan, Fluoride toothpastes for preventing dental caries in children and adolescents, Cochrane Database Syst. Rev. (2003) CD002278, https://doi.org/10.1002/14651858.CD002278.

[7] V.C.C. Marinho, H.V. Worthington, T. Walsh, L.Y. Chong, Fluoride gels for preventing dental caries in children and adolescents, Cochrane Database Syst. Rev. (2015) CD002280, https://doi.org/10.1002/14651858.CD002280.pub2.

[8] V.C.C. Marinho, H.V. Worthington, T. Walsh, J.E. Clarkson, Fluoride varnishes for preventing dental caries in children and adolescents, Cochrane Database Syst. Rev. (2013) CD002279, https://doi.org/10.1002/14651858.CD002279.pub2.

[9] A. Rosenblatt, T.C.M. Stamford, R. Niederman, Silver diamine fluoride: a caries "silverfluoride bullet", J. Dent. Res. 88 (2009) 116-125, https://doi.org/10.1177/0022034508329406. 
[10] J.A. Horst, Silver fluoride as a treatment for dental caries, Adv. Dent. Res. 29 (2018) 135140, https://doi.org/10.1177/0022034517743750.

[11] J. Burns, K. Hollands, Nano silver fluoride for preventing caries, Evid. Based Dent. 16 (2015) 8-9, https://doi.org/10.1038/sj.ebd.6401073.

[12] J.A. Teixeira, A.V.C. e Silva, V.E. dos Santos Júnior, P.C. de Melo Júnior, M. Arnaud, M.G. Lima, M.A.P. Flores, T.C.M. Stamford, J.R. Dias Pereira, A.G. Ribeiro Targino, A. Galembeck, A. Rosenblatt, Effects of a new nano-silver fluoride-containing dentifrice on demineralization of enamel and streptococcus mutans adhesion and acidogenicity, Int. J. Dent. (2018) article ID 1351925, https://doi.org/10.1155/2018/1351925.

[13] J.F. Hernandez-Sierra, F. Ruiz, D.C.C. Pena, F. Martinez-Gutierrez, A.E. Martinez, A. de Jesus Pozos Guillen, H. Tapia-Perez, G.M. Castanon, The antimicrobial sensitivity of Streptococcus mutans to nanoparticles of silver, zinc oxide, and gold, Nanomed. 4 (2008) 237-240, https://doi.org/10.1016/j.nano.2008.04.005.

[14] F. Li, M.D. Weir, A.F. Fouad, H.H.K. Xu, Effect of salivary pellicle on antibacterial activity of novel antibacterial dental adhesives using a dental plaque microcosm biofilm model, Dent. Mat. 30 (2013) 182-191, https://doi.org/10.1016/j.dental.2013.11.004.

[15] S. Agnihotri, M. Soumyo, M. Suparna, Size-controlled silver nanoparticles synthesized over the range 5-100 $\mathrm{nm}$ using the same protocol and their antibacterial efficacy, RSC Advances 4 (2014) 3974-3983, https://doi.org/10.1039/C3RA44507K.

[16] G.A. Martinez-Castanon, N. Nino-Martinez, F. Martinez-Gutierrez, J.R. MartinezMendonza, F. Ruiz, Synthesis and antibacterial activity of silver nanoparticles with different sizes, J. Nanoparticle Res. 10 (2008) 1343-1348, https://doi.org/10.1007/s11051008-9428-6.

[17] A.G.R. Targino, M.A.P. Flores, V.E. dos Santos Junior, F. de Godoy Bené Bezerra, H. de Luna Freire, A. Galembeck, A. Rosenblatt, An innovative approach to treating dental decay in children. A new anti-caries agent, J. Mater. Sci. Mater. Med. 25 (2014) 2041-2047, https://doi.org/10.1007/s10856-014-5221-5.

[18] S. Bjarnason, S.Y. Finnbogason, Effect of different fluoride levels in dentifrice on the development of approximal caries, Caries Res. 25 (1991) 207-212, https://doi.org/10.1159/000261369. 
[19] J. M. ten Cate, Current concepts on the theories of the mechanism of action of fluoride, Acta Odontol. Scand. 57 (1999) 325-329, https://doi.org/10.1080/000163599428562.

[20] J.D.B. Featherstone, Prevention and reversal of dental caries: role of low level fluoride, Commun. Dent. Oral Epidemiol. 27 (1999) 31-40, https://doi.org/10.1111/ j.1600-0528.1999.tb01989.x.

[21] R. J. M. Lynch, R. Navada, R. Walia, Low-levels of fluoride in plaque and saliva and their effects on the demineralisation and remineralisation of enamel; role of fluoride toothpastes, Int. Dent. J. 54, S5 (2004) 304-309, https://doi.org/10.1111/j.1875-595X.2004.tb00003.x.

[22] R.M. Duckworth, S.N. Morgan, C.K. Burchell, Fluoride in plaque following use of dentifrices containing sodium monofluorophosphate, J. Dent. Res. 68 (1989) 130-133, https://doi.org/10.1177/00220345890680020601.

[23] R.M. Duckworth, S.N. Morgan, R.J. Gilbert, Oral fluoride measurements for estimation of the anti-caries efficacy of fluoride treatments, J. Dent. Res. 71, 3 suppl (1992) 836-840, https://doi.org/10.1177/002203459207100S09.

[24] F. Lippert, A. Butler, R.J.M. Lynch, A.T. Hara, Effect of fluoride, lesion baseline severity and mineral distribution on lesion progression, Caries Res. 46 (2012) 23-30, https://doi.org/10.1159/000334787.

[25] F. Lippert, R.J.M. Lynch, G.J. Eckert, S.A. Kelly, A.T. Hara, D.T. Zero, In situ fluoride response of caries lesions with different mineral distributions at baseline, Caries Res. 45 (2011) 47-55, https://doi.org/10.1159/000323846.

[26] R.J.M. Lynch, J.M. Ten Cate, The effect of adjacent dentine blocks on the demineralisation and remineralisation of enamel in vitro, Caries Res. 40 (2006) 38- 42, https://doi.org/10.1159/000088904.

[27] G.L. Vogel, Z. Zhang, L.C. Chow, G.E. Schumacher, Changes in lactate and other ions in plaque and saliva after a fluoride rinse and subsequent sucrose administration, Caries Res. 36 (2002) 44-52, https://doi.org/10.1159/000057590.

[28] D.M. da Silva Ávila, R.F. Zanatta, T. Scaramucci, I.V. Aoki, C.R.G. Torres, A.B. Borges, Randomized in situ trial on the efficacy of Carbopol in enhancing fluoride / stannous antierosive properties, J. Dent. 101 (2020) 103347, https://doi.org/10.1016/j.jdent.2020.103347. 
[29] Q. Xi, W. Hoth-Hannig, S. Deng, X. Jin, B. Fu, M. Hannig, The effect of polyphenolcontaining solutions on in situ biofilm formation on enamel and dentin, J. Dent. 102 (2020) 103482, https://doi.org/10.1016/j.jdent.2020.103482.

[30] R.J. Wierichs, J. Musiol, D. Erdwey, M. Esteves-Oliveira, C. Apel, H. Meyer-Lueckel, Reand demineralization characteristics of dentin depending on fluoride application and baseline characteristics in situ, J. Dent. 94 (2020) 103305, https://doi.org/10.1016/j.jdent.2020.103305.

31] J.M. Ten Cate, Novel anticaries and remineralizing agents: prospects for the future, J.

Dent. Res. 91 (2012) 813-815, https://doi.org/10.1177/0022034512455032.

32] C.H. Chu, E.C. Lo, H.C. Lin, Effectiveness of silver diamine fluoride and sodium fluoride varnish in arresting dentin caries in Chinese pre-school children, J. Dent. Res. 81 (2002) 767-770, https://doi.org/10.1177/0810767.

[33] J.E. Frencken, M.C. Peters, D.J. Manton, S.C. Leal, V.V. Gordan, E. Eden, Minimal intervention dentistry for managing dental caries - a review, Report of a FDI task group, Int. Dent. J. 62 (2012) 223-243, https://doi.org/10.1111/idj.12007.

[34] A. Youssef, M. Farid, M. Zayed, E. Lynch, M.K. Alam, A.M. Kielbassa, Improving oral health: a short-term split-mouth randomized clinical trial revealing the superiority of resin infiltration over remineralization of white spot lesions, Quintessence Int. 51 (2020) 696-709, https://doi:10.3290/j.qi.a45104.

[35] C. Deery, Silver lining for caries cloud? Evid. Based Dent. 10 (2009) 68, https://doi.org/10.1038/sj.ebd.6400661.

[36] Q.H. Zhi, E.C. Lo, A.C. Kwok, An in vitro study of silver and fluoride ions on remineralization of demineralized enamel and dentine, Aust. Dent. J. 58 (2013) 50-56, https://doi.org/10.1111/adj.12033.

[37] F. Schäfer, S.J. Raven, T.A. Parr, The effect of lesion characteristic on remineralization and model sensitivity, J. Dent. Res. 71 (special issue) (1992) 811813, https://doi.org/10.1177/002203459207100S03.

[38] A. Labanni, Zulhadjri, D. Handayani, Y. Ohya, S. Arief, Size controlled synthesis of well distributed nano-silver on hydroxyapatite using alkanolamine compounds, Ceram. Int. 46 (2020) 5850-5855, https://doi.org/10.1016/j.ceramint.2019.11.035. 
[39] A.M. Kielbassa, M.R. Leimer, J. Hartmann, S. Harm, M. Pasztorek, I.B. Ulrich, Ex vivo investigation on internal tunnel approach/internal resin infiltration and external nanosilver-modified resin infiltration of proximal caries exceeding into dentin, PLoS. One. 15 (2020) e0228249, https://doi.org/10.1371/journal.pone.0228249.

[40] D. Ricucci, J.F. Siqueira Jr, Bacteriologic status of non-cavitated proximal enamel caries lesions. A histologic and histobacteriologic study, J. Dent. 100 (2020) 103422, https://doi.org/10.1016/j.jdent.2020.103422. 


\section{Figure Legends}

Fig. 1. Schematic study design.

Fig. 2. Schematic specimen drawing.

Fig. 3. The effect of different fluoride concentrations on (changes in) the mineral loss (A) and lesion depth (B) of the demineralized enamel specimens after (secondary) demineralization. Values indicated by different letters are statistically different from each other $(\mathrm{p}<0.05)$ within the same lesion severity group. *Asterisks indicate significant differences compared to baseline values before demineralization $(\mathrm{p}<0.05)$.

Fig. 4. The effect of silver nanoparticles on (changes in) the mineral loss (A) and lesion depth (B) of the demineralized enamel specimens after (secondary) demineralization. Values indicated by different letters are statistically different from each other $(p<0.05)$ within the same lesion severity group. *Asterisks indicate significant differences compared to baseline values before demineralization $(\mathrm{p}<0.05)$.

Fig. 5. Changes in the mean mineral distribution profiles after (secondary) demineralization for initially sound enamel specimens (A) and enamel caries-like lesions initially demineralized for 1 (B), 6 (C) and 15 (D) days. 
Table 1. TMR baseline data [mean (standard deviation)] for all treatment groups

\begin{tabular}{|c|cc|c|c|c|c|}
\hline Variable & Fluoride [ppm] & Silver [ppm] & Sound enamel & 1-day lesions & 6-day lesions & 15-day lesions \\
\hline$\Delta \mathrm{Z}$ & 0 & 0 & $167(161)$ & $1016(433)$ & $2351(649)$ & $3668(923)$ \\
{$[\mathrm{vol} \% \mathrm{~min} \times \mu \mathrm{m}]$} & 0 & 10 & $126(85)$ & $800(242)$ & $2669(743)$ & $3972(1264)$ \\
& 1 & 0 & $179(152)$ & $903(222)$ & $2770(915)$ & $3679(899)$ \\
& 1 & $123(124)$ & $866(235)$ & $2901(790)$ & $3551(1140)$ \\
& 10 & 10 & $158(129)$ & $696(282)$ & $2812(660)$ & $3494(1340)$ \\
& 10 & 0 & $187(154)$ & $637(180)$ & $2859(816)$ & $3385(983)$ \\
\hline $\mathrm{L}$ & 0 & 0 & $8.9(15.7)$ & $47.4(19.3)$ & $102.3(28.1)$ & $158.7(21.9)$ \\
& 0 & $4.9(2.6)$ & $36.9(10.9)$ & $106.1(16.8)$ & $166.0(32.7)$ \\
& 1 & 10 & $5.7(4.2)$ & $43.0(12.1)$ & $116.7(37.1)$ & $152.2(23.9)$ \\
& 1 & 0 & $3.9(1.3)$ & $40.1(15.2)$ & $115.3(31.0)$ & $149.8(30.7)$ \\
& 10 & 10 & $5.2(2.1)$ & $37.5(14.7)$ & $115.2(25.4)$ & $149.6(33.7)$ \\
& 10 & 0 & $6.6(6.4)$ & $31.9(12.0)$ & $115.2(33.5)$ & $152.2(32.4)$ \\
\hline
\end{tabular}




\section{Primary Demineralization of Enamel Specimens}

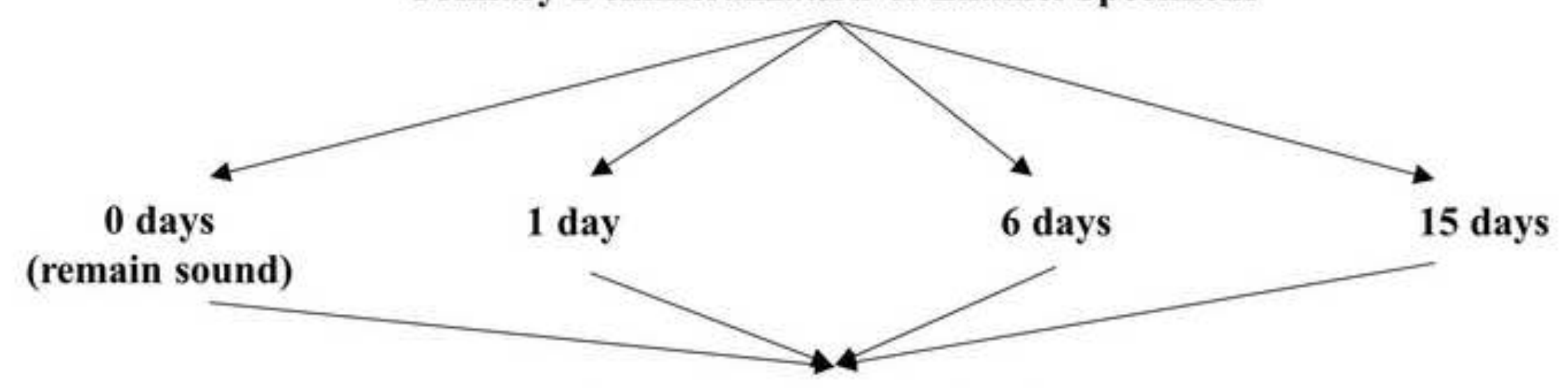

Secondary Demineralization

in the presence of:

0 ppm $\mathrm{F}+0$ ppm Ag (control)

0 ppm $\mathrm{F}+10 \mathrm{ppm} \mathrm{Ag}$

$1 \mathrm{ppm} \mathrm{F}+0$ ppm Ag

$1 \mathrm{ppm} \mathrm{F}+10 \mathrm{ppm} \mathrm{Ag}$

$10 \mathrm{ppm} \mathrm{F}+0 \mathrm{ppm} \mathrm{Ag}$

$10 \mathrm{ppm} \mathrm{F}+10 \mathrm{ppm} \mathrm{Ag}$

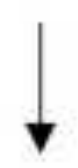

TMR analysis:

Integrated Mineral Loss $[\Delta(\Delta) \mathrm{Z}]$

Lesion Depth $[(\Delta) \mathrm{L}]$ 


\section{TMR Sectioning after (secondary) demineralization}

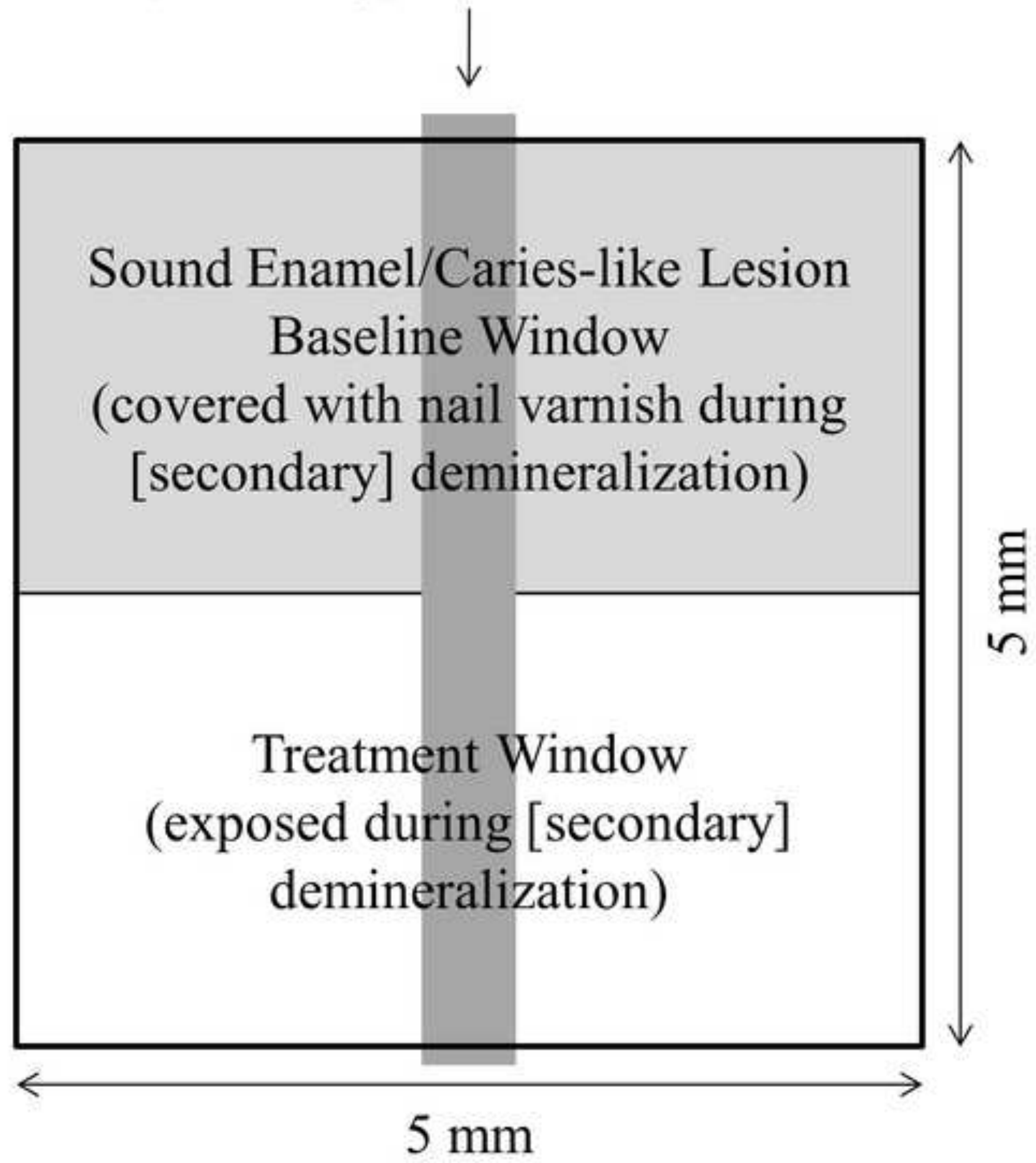


A.

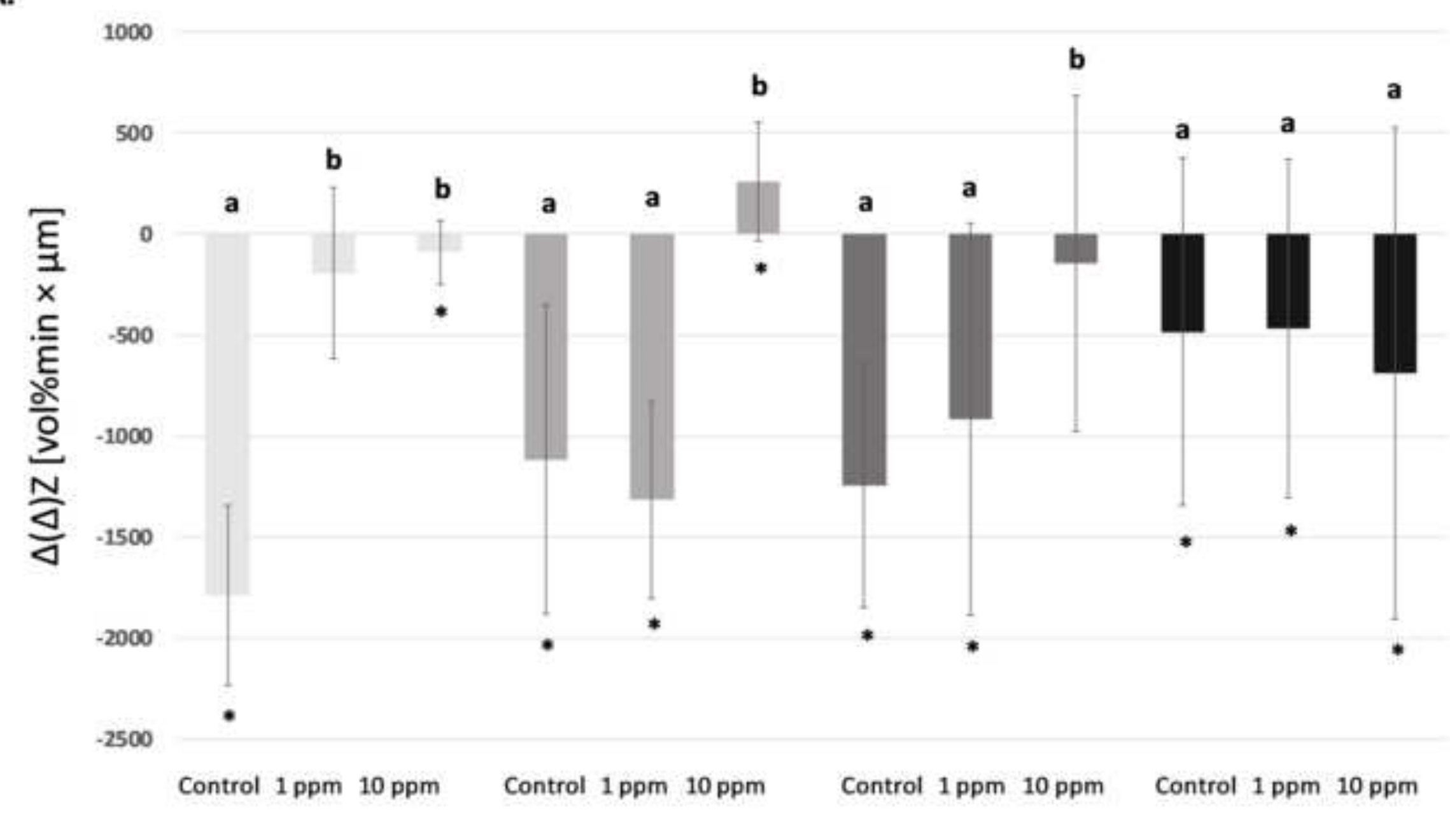

$\square$ 0-day

ए 1-day

6-day

15-day

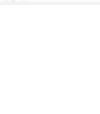

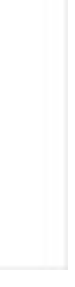


B.

120

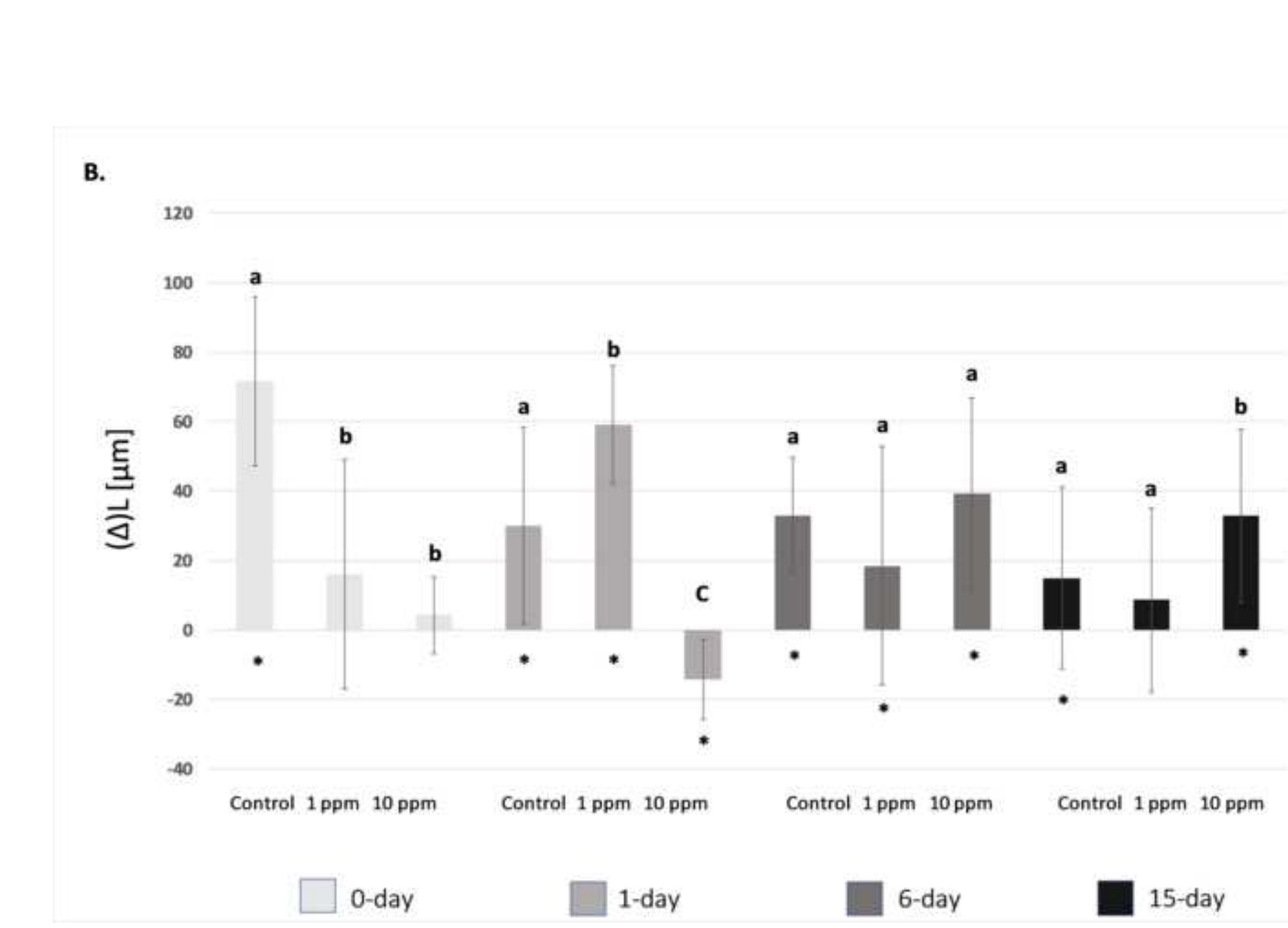

$-40$

Control $1 \mathrm{ppm} 10 \mathrm{ppm} \quad$ Control $1 \mathrm{ppm} 10 \mathrm{ppm} \quad$ Control $1 \mathrm{ppm} 10 \mathrm{ppm} \quad$ Control $1 \mathrm{ppm} 10 \mathrm{ppm}$

120

W 0-day $\quad$ 1-day $\quad$ 6-day 15-day
O-da

(1)


A.

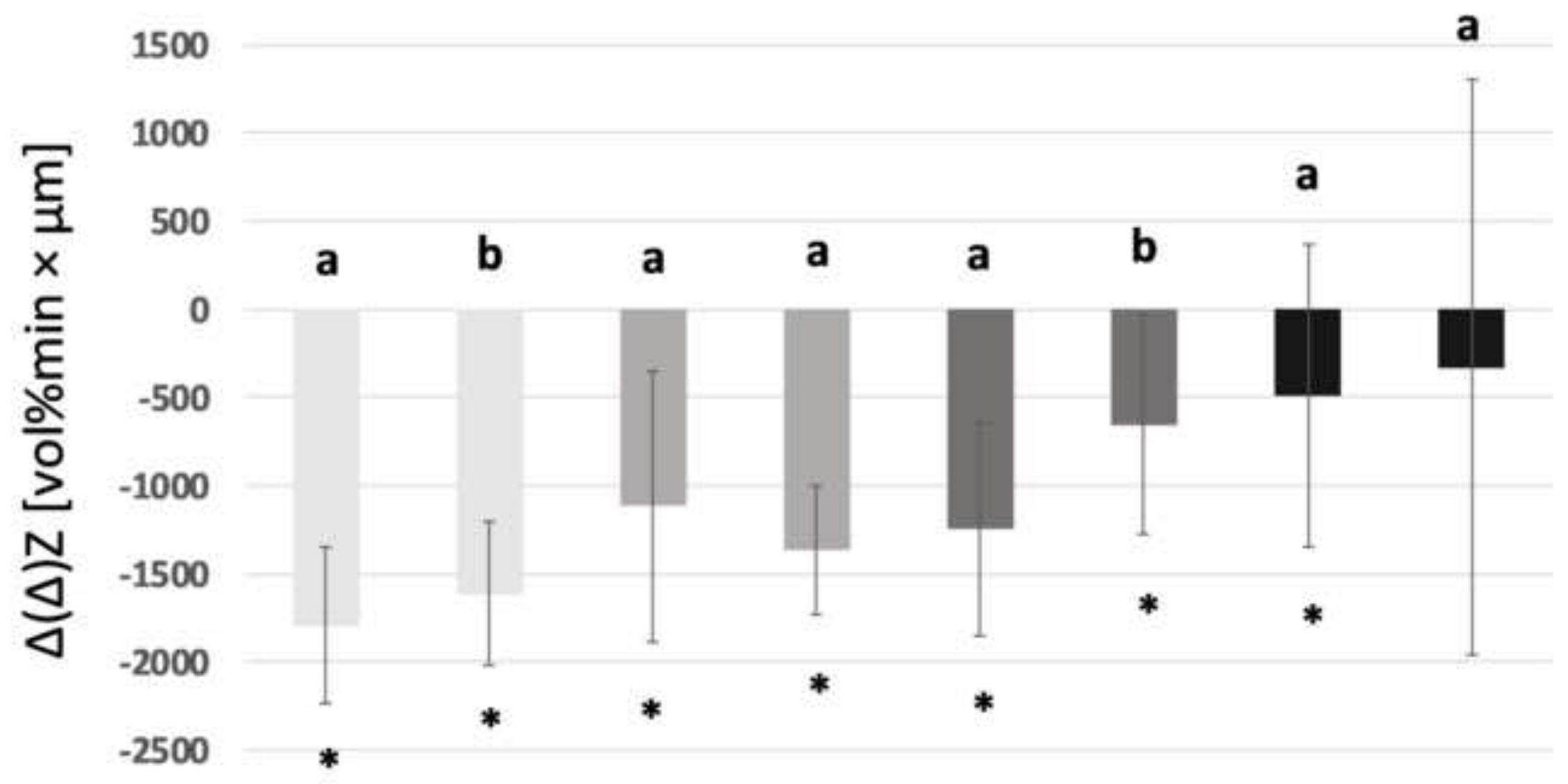

Control $10 \mathrm{ppm}$ Control $10 \mathrm{ppm}$ Control $10 \mathrm{ppm}$ Control $10 \mathrm{ppm}$
$\square$ 0-day
1-day
6-day

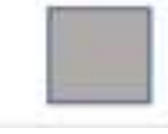
1-day
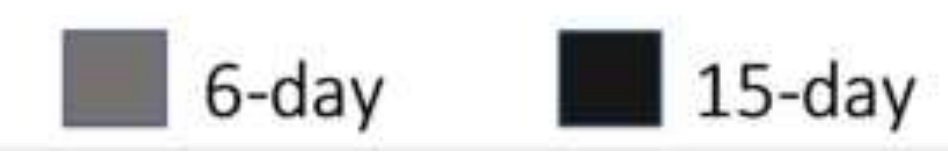
B.

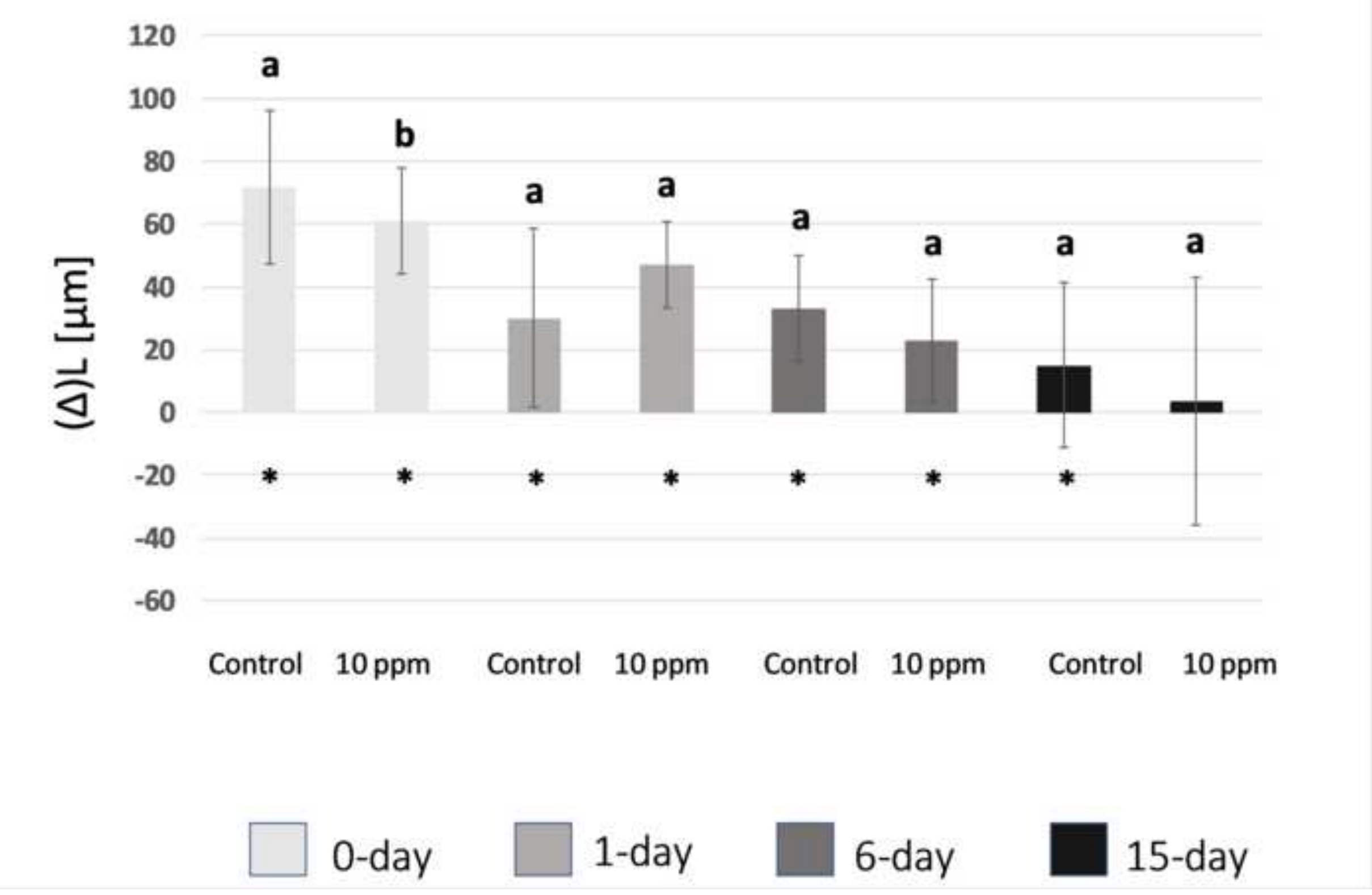

Control $10 \mathrm{ppm}$ Control $10 \mathrm{ppm}$ Control $10 \mathrm{ppm}$ Control $10 \mathrm{ppm}$

$\square$ 0-day $\square$ 1-day $\square$ 6-day $\square$ 15-day


A.
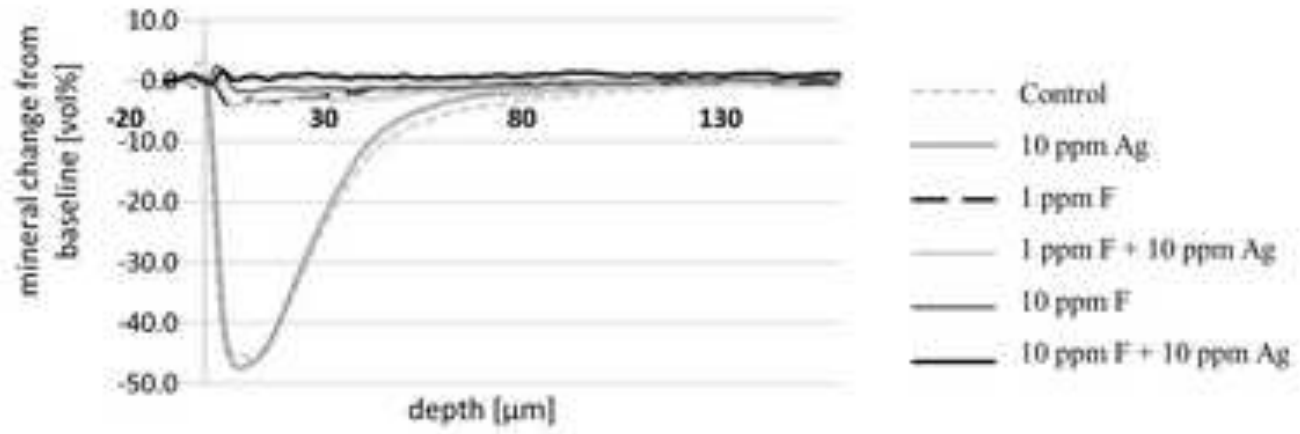

B.
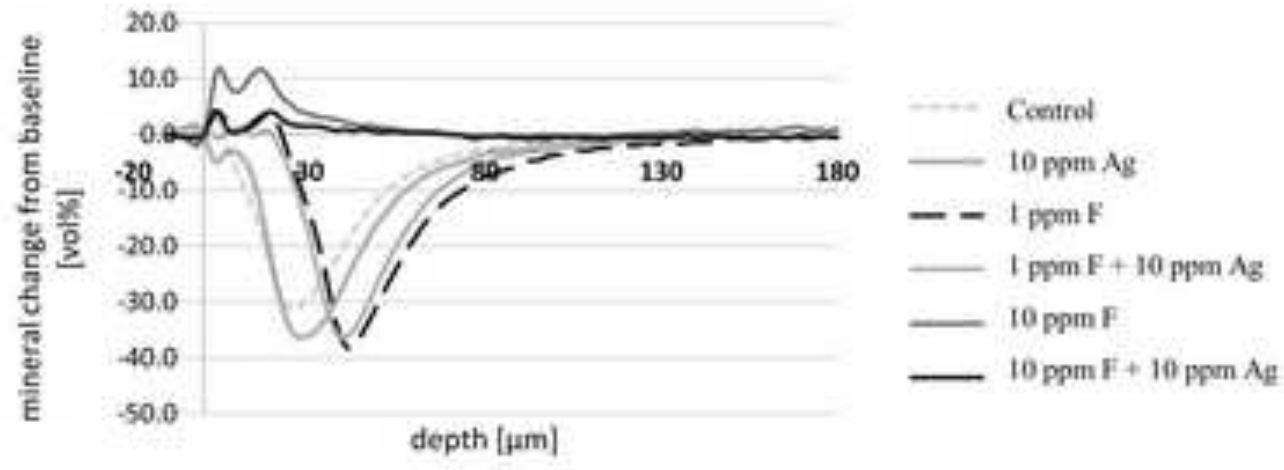

c.
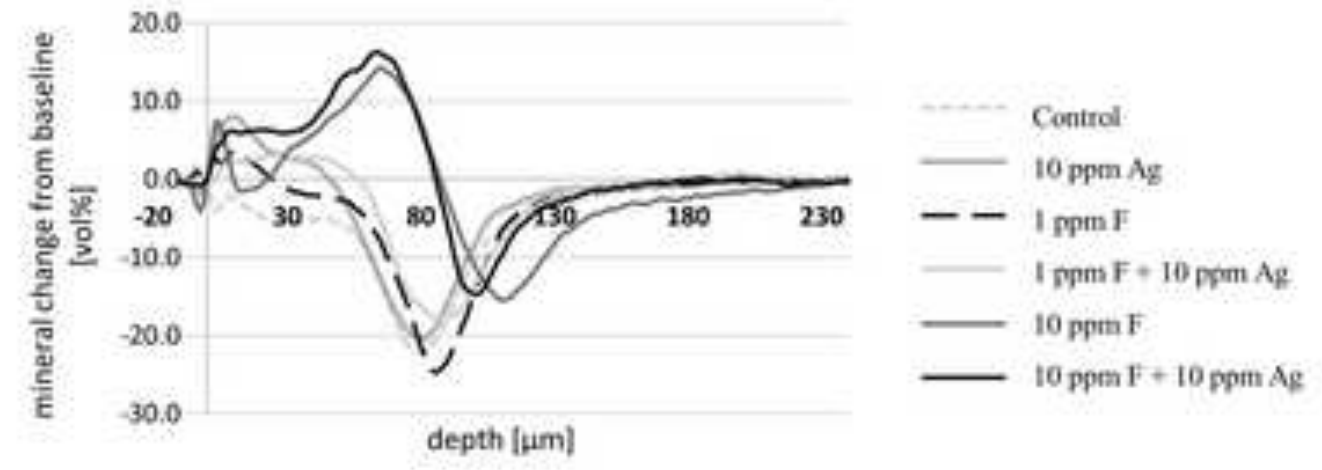

D.
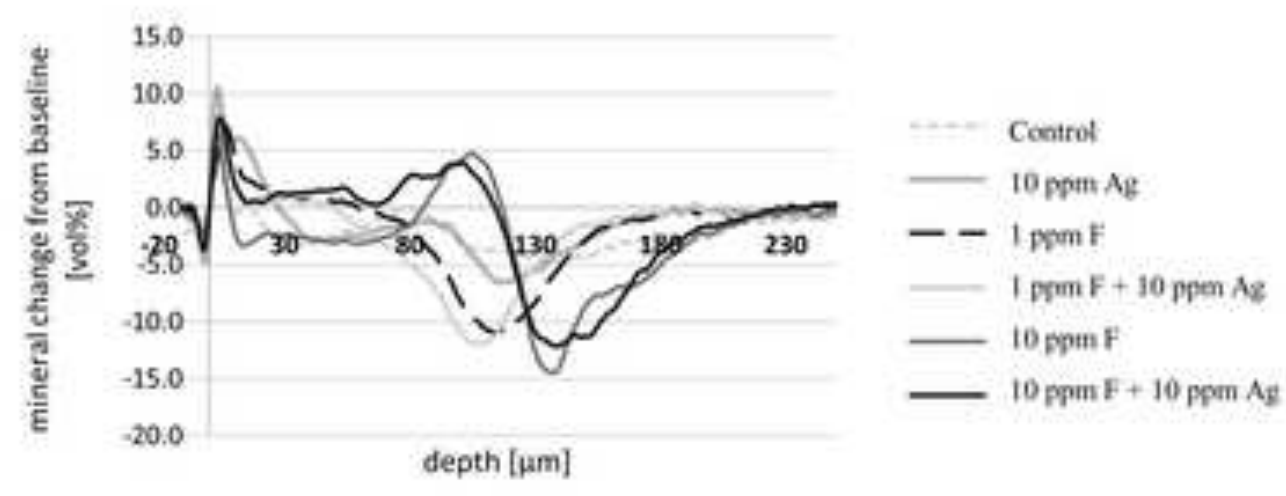

D. 


\section{Acknowledgments}

Dr. Aldhaian received a scholarship from King Saud Bin Abdulaziz University for Health Sciences, College of Dentistry, Riyadh, Saudi Arabia. This research is to be submitted for the fulfillment of his MSD degree in Dental Sciences at Indiana University School of Dentistry (IUSD). This project was supported by Remineralization Research Program of the Oral Health Research Institute at IUSD. The authors are thankful to Mr. Adam B. Kelly, Mrs. Jennifer Eder and Mr. Nyi-Nyi Tin for their assistance in the laboratory. 
${ }^{*}$ Conflict of Interest Statement

\section{Conflict of Interest}

The authors declare no conflict of interest. 
Bader A. Aldhaian: Conceptualization; Data curation; Investigation; Methodology; Project administration; Visualization; Writing - original draft

Abdulrahman A. Balhaddad: Data curation; Investigation; Writing - original draft

Areej A. Alfaifi: Data curation; Investigation; Writing - original draft

John A. Levon: Methodology; Writing - review \& editing

George J. Eckert: Formal analysis; Writing - review \& editing

Anderson T. Hara: Conceptualization; Methodology; Writing - review \& editing

Frank Lippert: Conceptualization; Investigation; Methodology; Project administration;

Resources; Supervision; Visualization; Writing - review \& editing 
- The effect of silver nanoparticles and fluoride on demineralization prevention was investigated.

- Both silver nanoparticles and fluoride afforded demineralization prevention.

- Their effect was independent of one another.

- Baseline caries lesion severity affected the extent of demineralization.

- Fluoride and silver nanoparticles may allow for more tailored caries prevention. 